\title{
The Role of Self-Efficacy Beliefs and Social Support on Prediction of Addiction Relapse
}

\author{
Zahra Nikmanesh, ${ }^{1,{ }^{*}}$ Mohamad Hossin Baluchi, ${ }^{2}$ and Ali Akbar Pirasteh Motlagh ${ }^{3}$ \\ ${ }^{1}$ Department of Psychology, Faculty of Education and Psychology, University of Sistan and Baluchestan, Zahedan, IR Iran \\ ${ }^{2}$ Department of Education, University of Sistan and Baluchestan, Zahedan, IR Iran \\ ${ }^{3}$ Department of Psychology, Organization of Education, Yasuj, IR Iran \\ "Corresponding author: Zahra Nikmanesh, Department of Psychology, Faculty of Education and Psychology, University of Sistan and Baluchestan, Zahedan, IR Iran. E-mail: \\ zahranikmanesh@yahoo.com
}

Received 2014 June 16; Revised 2015 October 24; Accepted 2015 November 18.

\begin{abstract}
Background: Addiction is a physiological and psychological and social disorder that consider as a huge-health problem in many societies.

Objectives: The present study aimed to investigate the role of self-efficacy beliefs and social support on prediction of addiction relapse.

Patients and Methods: The research method was a causal-comparison. The population of the study included all subjects who sought medical advice in the centers for addiction treatment in Saravan and Iranshahr, south-east of Iran. The study population included 166 participants (83 participants without relapse and 83 participants with relapse) selected using snowball sampling during a four-month period of voluntary participation in the centers. The variables were measured by general self-efficacy scale and Multidimensional Scale of Perceived Social Support. The data were analyzed by MANOVA.

Results: Findings revealed significant differences between participants without relapse and participants with relapse in terms of "self-efficacy beliefs" and "social support". The two variables of self-efficacy beliefs and social support were the best predictors of addiction relapse.

Conclusions: Based on the findings of the study, it can be concluded that self-efficacy beliefs and social support play effective roles in preventing patients from addiction relapse.

Keywords: Behavior, Addictive, Recurrence, Self Efficacy, Social Support
\end{abstract}

\section{Background}

Addiction is a physiological, psychological and social disease (1), which arises from overuse and misuse of substances such as alcohol, opium, hashish, etc., and causes a dependence on the substances, leaving adverse physiological, psychological and social impacts (2). From the psychiatric and medical perspectives, the substance-dependent individual is a patient and like other diseases, his/her disease requires primary and secondary preventions. In the primary prevention, providing information about addiction problems in terms of physical, psychological, social and economic issues should receive high attention to avoid addiction relapse later in life, in the secondary prevention, follow-up therapeutic measures seem essential to prevent the relapse of addiction, particularly when the patient is relatively recovered with the help of medical and psychological advice. Since addiction, unlike other disorders, has not received preventive medical care, limited success is achieved in terms of prevention of drug addiction before and after the addiction (3); therefore, a large population of people who are dependent on the drug abuse restart drug addiction after their drug withdrawal. In Iran, this ratio is reported 38 to $90 \%$ (4).

Several studies conducted on drug dependent people revealed the significant effects of psychological factors on decreasing the risk of addiction and improving its successful treatment. Self-efficacy belief is one of the psychological factors that impacts on the success of treatment. The self-efficacy belief is a cognitive-motivational force that determines the individuals' appropriate coping level when his/her skills and abilities are under pressure. Poor self-efficacy beliefs divest the individuals' problemsolving ability (5). Several studies claimed that self-efficacy has a special role in prediction of treatment outcomes and improvement in the health of drug-dependent people. For instance, Ibrahim et al. found a significant negative relationship between self-efficacy and addiction relapse. Individuals who have low self-efficacy are more likely to continue their drug abuse (6). Torrecillas et al. showed that self-efficacy is indirectly related to the quantity of drugs dependence (7). Abdollahi et al. found relationships between relapse and self-efficacy and also between self-efficacy and 
age of the first drug use (8).

Dolan et al. reported that people with high self-efficacy have a greater tendency to discontinue the substance abuse and also are less insistent on drug abuse in the face of the risk for substance abuse. Moreover, self-efficacy can only predict drug abuse for three months after treatment (9). Furthermore, Moos and Moos stated that people with high self-efficacy are likely to avoid alcoholic beverages for three years. On the other hand, people with low selfefficacy are likely to relapse from alcohol withdrawal (10). In other research studies, Ramo et al., McKay et al., Walton et al., Vielva et al., Maisto et al., and Solomon and Annis reported a negative relationship between self-efficacy and relapse of drug abuse after cessation. They also concluded that people with high self-efficacy have higher levels of selfconfidence and are able to resist against drugs including alcohol, crack and cocaine for several months (11-16).

Furthermore, given that addiction is a disease, it requires support far more than physical diseases. In addition to receiving medical and medicinal care, social and psychological support processes should be focused on patients with substance abuse, particularly after medicinal treatment. The process of withdrawal and putting an end to the relationships with substance-dependent peers is extremely stressful and requires social-supportive relationships and resources. Hence, social support is among the factors that have a special role in maintaining the withdrawal of drug-dependent people (17). Taylor et al. argued that social support is generally a concept in which someone receives help from nearby persons to solve the problems he/she has encountered (18). Lee et al. defined social support as the strangest device to cope with chronic illness and tensions that make it humble and easy to encounter the problems (19). Atadokht et al. revealed that perceived social support from family and the family expressed emotions predicted $12 \%$ of addiction relapse (20). Nashee et al. showed a negative relationship between perceived social support and addiction relapse (21).

Researches conducted by Lemos et al., Martin-Storey et al., Jason et al., Atkins et al., Ellis et al. showed that positive factors such as family support can help the addiction cessation. Also, providing tips and information (support information) raises drug-dependent individuals' commitment and therefore these people are more successful in quitting than the ones who are not provided with such information and guidance (22-26).

Although in many studies social support is considered as an important factor in the withdrawal of drugdependent people, some researchers such as Macdonald et al. (27) showed that social support is not always an effective predictor of recovery steps, and other conditions may contribute to the effectiveness of social support.
However, there were some researches on the relationship of self-efficiency and social support with drug dependence, but they did not compare the effectiveness of the variables. The current research also emphasized the relapse.

\section{Objectives}

Therefore, according to what was mentioned earlier, considering the psychological significance of social support and self-efficacy beliefs and given that addiction is one of the fundamental psychological health issues, the present study aimed to examine the role of self-efficacy and social support on prediction of addiction relapse, which has not received much attention in Iran.

\section{Patients and Methods}

The present study examined the role of self-efficacy and social support variables to predict addiction relapse. In the current study, the criterion variable was the addiction state (relapse or non-relapse) and predictor variables were selfefficacy and social support.

The population of the study included all drugdependent individuals, applicants for withdrawal from addiction, residing in Nikshahr, Saravan and Iranshahr in Sistan and Baluchestan, who referred to addiction treatment camps in Saravan and Iranshahr during the past five years. Sampling was conducted from December to March 2012, through voluntarily Snowball sampling method. After identifying each member and obtaining his/her willingness to cooperate, he/she aided to find other subjects for data collection. Thus, the sample contains 166 individuals, including 83 patients without relapse and 83 patients with relapse. The group of drug-dependent individuals without relapse included those individuals who referred to two addiction treatment camps in Iranshahr and Saravan and had quitted from one month to five years. The group of drug-dependent individuals with relapse included those who had relapsed repeatedly and had quitted from one month to five years.

After identifying individuals belonging to the study population and justifying them by the researcher or her colleagues through explaining the intention of the study and ensuring them that their information will remain confidential, the participants were asked to fill out the questionnaire. People who were literate enough to read and write were asked to complete the questionnaire in the presence of the researcher or a colleague and hand it over to them. It is evident that the researcher or a colleague read the questionnaire for those who were illiterate or were not 
literate enough to read and write and completed the questionnaire.

The data collection instrument was general selfefficacy questionnaire developed by Sherer et al. (28). The questionnaire contains 17 items based on a five-point Likert scale. The items were designed to have different points from one to five. Therefore, the lowest self-efficacy score on the questionnaire is 17 and the maximum score is 85 . Except for questions 3, 8, 9, 13 and 15 all items are reversely scored. The internal consistency coefficient of the scale was calculated 0.83 by Haghayegh et al. (29). To examine the criterion validity, they calculated the correlation of the scale with the Rotter's internal locus of the control attribution as $\mathrm{r}=0.342$ which was significant at $\mathrm{P}<0.01$ (29). In the present study, the coefficient alpha for this scale was 0.82 .

Multidimensional Scale of Perceived Social Support (MSPSS) is a 12-item multidimensional instrument to assess perceived social support from three sources of family, friends and important people in life developed by Zimet et al. (30). MSPSS assesses the multidimensional scale of perceived social support by the respondents in each of the three domains. This scale has desirable internal consistency. Zaki reported the Cronbach's alpha of the questionnaire about 0.88 (31). In the present study, the Cronbach's coefficient alpha of the scale was 0.89. Both descriptive and inferential statistics were used for data analysis. For descriptive statistics, parameters such as mean, frequency and percentage and for inferential statistics, Independent t-test and Logistic regression were applied.

\section{Results}

Findings related to the demographic variable of participants' age showed that the age group of 30 - 43 with $26.5 \%$ had the highest frequency and the age group of 44 - 57 with $3.6 \%$ had the lowest frequency among drug-dependent individuals without relapse. In contrast, the age group of 16 - 29 with $26.5 \%$ had the highest frequency and the age group of 44 - 57 with $6.6 \%$ had the lowest frequency among drug-dependent individuals with relapse. Frequency distribution of participants according to their educational level indicated that $9.6 \%$ of the individuals without relapse had primary education or less. Middle and high school educational level with $32 \%$ was the most frequent educational level among drug-dependent individuals without relapse. However, individuals with primary education and less in the drug-dependent group who had relapsed was $5.4 \%$ and middle and high school educational level with $39.8 \%$ had the highest frequency among the individuals with relapse. Considering participants' employment status, results showed that the unemployed and employed in- dividuals in drug-dependent individuals without relapse were 6.6 and $43.4 \%$, respectively. However, among the drug-dependent individuals with relapse, the rates of unemployed and employed were 7.2 and $42.8 \%$, respectively. Moreover, the results of frequency distribution regarding participants' marital status revealed that the frequency of married and single individuals among those who had not relapsed were 32.7 and $16.3 \%$, respectively; while among those experiencing relapses, the single and married individuals were 21.1 and $28.9 \%$, respectively.

To answer the question that whether self-efficacy beliefs and social support have significant roles in prediction of addiction relapse, MANOVA was used and the two groups of drug-dependent individuals with and without relapse were compared.

Prerequisite for MANOVA was the Levin variances homogeneity shown in Table 2, there was no significant difference between the mean score of the two groups in selfefficiency beliefs but for that of social support it was not significant only in level $\mathrm{P} \leq 0.01$.

Tables 3 and 4 show the MANOVA results for both selfefficiency beliefs and social support. The results of Table 3 indicated a significant different between the two groups, with and without relapse. Therefore, ANOVA was conducted for each of the variables.

Table 4 shows that $\mathrm{F}$ for self-efficiency was 34.75 and significant in 0.000 . Therefore, the two groups, subjects with and without addiction relapse, are different in self-efficacy beliefs. Mean score of self-efficacy in without relapse group was more than that of the group with relapse. Also these results showed that social support F was 46.41 and significant in 0.000 . Therefore there was a significant difference between the two groups, subjects with and without addiction relapse. In the without relapse group, mean score of social support was more than that of the group with relapse.

The Eta shows that self-efficacy predicts 0.17 of changes in the addiction relapse but social support predicts 0.22 of its changes.

\section{Discussion}

The current study aimed to investigate the role of selfefficacy beliefs and social support on prediction of addiction relapse. The results showed that individuals without relapse, compared to the ones with relapse, had higher selfefficacy beliefs and better social support. Moreover, the Eta square results showed that self-efficacy of 0.17 and social support variables of 0.22 predict addiction relapse; social support was a more effective predictor.

The results of the research questions about the role of self-efficacy beliefs in predicting addiction relapse were consistent with those of the previous studies conducted by 
Table 1. Characteristics of the Subjects ${ }^{\mathrm{a}}$

\begin{tabular}{|c|c|c|c|}
\hline Variables & Without Relapse & With Relapse & Total \\
\hline \multicolumn{4}{|l|}{ Age, $y$} \\
\hline $16-29$ & $33(19.9)$ & $44(26.5)$ & $77(46.4)$ \\
\hline $30-43$ & $44(26.5)$ & $28(16.9)$ & $72(43.4)$ \\
\hline $44-57$ & $6(3.6)$ & $11(6.6)$ & $17(10.2)$ \\
\hline \multicolumn{4}{|l|}{ Education } \\
\hline Primary school and less & $16(9.6)$ & $9(5.4)$ & $25(15)$ \\
\hline Middle and high school & $53(32)$ & $66(39.8)$ & $119(71.6)$ \\
\hline Higher education & $14(8.4)$ & $8(4.8)$ & $22(13.3)$ \\
\hline \multicolumn{4}{|l|}{ Employment } \\
\hline Unemployed & $11(6.6)$ & $12(7.2)$ & $23(13.9)$ \\
\hline Employed & $72(43.4)$ & $71(42.8)$ & $143(86.1)$ \\
\hline \multicolumn{4}{|l|}{ Marital Status } \\
\hline Single & $27(16.3)$ & $35(21.1)$ & $62(37.3)$ \\
\hline Married & $56(33.7)$ & $48(28.9)$ & $104(62.7)$ \\
\hline
\end{tabular}

${ }^{\mathrm{a}}$ values are expressed as No. (\%).

Table 2. Results of the Levin Variance Homogeneity for the Two Groups

\begin{tabular}{lcccc}
\hline Variables & F & df 1 & df 2 & 1 \\
\hline Self-efficiency & 1.07 & 0.30 & 164 \\
Social support & 4.06 & 1 & 164 \\
\hline
\end{tabular}

Table 3. Result of MANOVA Tests for the Two Groups

\begin{tabular}{|c|c|c|c|c|c|}
\hline Effect & Value & $\mathbf{F}$ & df 1 & df 2 & $\mathbf{P}$ \\
\hline Pillar trace & 0.26 & 28.57 & 2 & 163 & 0.000 \\
\hline Wilks lambda & 0.26 & 28.57 & 2 & 163 & 0.000 \\
\hline Hotelling trace & 0.26 & 28.57 & 2 & 163 & 0.000 \\
\hline Roy largest root & 0.26 & 28.57 & 2 & 163 & 0.000 \\
\hline
\end{tabular}

Tables 4. Results of ANOVA for Self-Efficacy Beliefs and Social Support

\begin{tabular}{|c|c|c|c|c|c|c|}
\hline Dependent Variables & Sum of Squares & df & Mean of Squares & $\mathbf{F}$ & $\mathbf{P}$ & Eta Square \\
\hline Self-efficacy & 3788.24 & 1 & 3788.24 & 34.75 & 0.000 & 0.17 \\
\hline Social support & 9777.56 & 1 & 9777.56 & 46.41 & 0.000 & 0.22 \\
\hline
\end{tabular}

Ibrahim et al. (6), Dolan et al. (9), Moos and Moos (10), Ramo et al. (11), McKay et al. (12), Walton et al. (13), Vielva and Iraurgi (14), Maisto et al. (15) and Solomon and Annis (16). Dolan et al. (9) showed that people with higher selfefficacy are more likely to discontinue drug abuse. Ramo et al. (11) also proposed that self-efficacy is associated with a protective role about drug abuse.

Similarly, McKay et al. (12) indicated that people with higher self-efficacy beliefs are more self-protective and more successful at quitting drug abuse. Therefore, selfefficacy beliefs can help drug-dependent individuals withdraw from addiction. An addict who believes that he/she 
cannot gain anticipated outcomes out of the drug cessation or that he/she cannot prevent unacceptable behavior, will lose his/her motivation to quit addiction. However, addicts with high self-efficacy beliefs have higher motivation and effort for decision-making; therefore, they achieve greater success in many issues such as withdrawal from drug abuse.

Moreover, findings of the present study about the role of social support in addiction relapse were consistent with those of previous studies by Lemos et al. (22), Martin-Storey et al. (23), Jason et al. (24), Atkins and Hawdon (25) and Ellis et al. (26). However, the results were not in line with those of the study by MacDonald et al. (27). Lemos et al. (22) showed that people with lower scores on social support were more likely to turn to substance abuse. Martin-Storey et al. (23) stated that low levels of perceived social support were associated with substance abuse. In addition, Jason et al., Atkins and Hawdon, and Ellis et al. indicated that positive factors such as family support can contribute to the withdrawal from addiction (24-26). However, MacDonald et al. (27) suggested that social support is not always an effective predictor of addiction recovery processes. Despite all this, companionship and empathy can reduce many undesirable effects of stress that patients incur in life; if such patients feel that there are people who care about them and help them with stressful situations, they will be less stricken by mental health problems including addiction and the following treatments. Considering the prior studies and the findings of the present study, it can be concluded that the treatment plan and medical preventions that include diagnosis and treatment do not suffice, and special programs and actions for addiction relapse prevention should be adopted. According to the findings of the current study, self-efficacy beliefs and social support can play a key role to prevent drug addiction relapse of individuals under treatment. It is suggested that providing necessary trainings associated with building self-efficacy beliefs and creating social support networks for under treatment patients should be placed on educational priorities. Moreover, addiction treatment centers should attempt to provide the essential conditions to improve self-efficacy beliefs and social support to prevent patients from addiction relapse.

The main limitation of the current research was difficulty of sampling because the data about such subjects were secret and health centers did not disclose them. Therefore the method of snowball sampling was used. The questionnaires were the main instrument for data gathering.

According to the obtained results it is necessary that addiction treatment centers improve self-efficiency beliefs and social support.

\section{Acknowledgments}

Authors are deeply thankful to all of the participants who cooperated in this research.

\section{Footnotes}

Authors' Contribution: Zahra Nikmanesh developed the original idea and the protocol, and Ali Akbar Pirasteh Motlagh contributed in the development of the prepared manuscript and wrote the manuscript. Mohamad Hossin Baluchi gathered and analyzed the data.

Financial Disclosure: This research was conducted as a dissertation for MA in the University of Sistan and Baluchestan.

\section{References}

1. Galanter M. Innovations: alcohol \& drug abuse: spirituality in Alcoholics Anonymous: a valuable adjunct to psychiatric services. Psychiatr Serv. 2006;57(3):307-9. doi: 10.1176/appi.ps.57.3.307. [PubMed: 16524986].

2. West R. Theory of Addiction, Blackwell publishing. oxford: World Health Organization; 2006.

3. Yonesi J, Mohammadi MR. Using the approach of publishing information on programs to prevent drug addiction among teenagers. Daneshvar Raftar J. 2006;13(16):1-10.

4. Sahand B, Zare H, Fata L. The Comparison of Early Maladaptive Schema's Domains between Successful and Non-Successful Opiate Addicts and Non-Clinical. Research on addiction. 2008;11(3):65-82.

5. Reeve JM. Understanding Motivation and emotion. Tehran: Editing Publishing; 2005.

6. Ibrahim F, Kumar N, Samah BA. Self efficacy and relapsed addiction tendency: An empirical study. Soc Sci. 2011;6(4):277-82.

7. Torrecillas FL, Torres Cobo MA, Delgado P, Ucles IR. Predictive Capacity of Self-Efficacy in Drug Dependence and Substance Abuse Treatment. Journal of Psychology and Clinical Psychiatry. 2015;2(3):1-7.

8. Abdollahi Z, Taghizadeh F, Hamzehgardeshi Z, Bahramzad O. Relationship between addiction relapse and self-efficacy rates in injection drug users referred to Maintenance Therapy Center of Sari, 1391. Glob J Health Sci. 2014;6(3):138-44. doi: 10.5539/gjhs.v6n3p138. [PubMed: 24762356].

9. Dolan SL, Martin RA, Rohsenow DJ. Self-efficacy for cocaine abstinence: pretreatment correlates and relationship to outcomes. Addict Behav. 2008;33(5):675-88. doi:10.1016/j.addbeh.2007.12.001. [PubMed: 18191329].

10. Moos RH, Moos BS. Rates and predictors of relapse after natural and treated remission from alcohol use disorders. Addiction. 2006;101(2):212-22. doi: 10.1111/j.1360-0443.2006.01310.x. [PubMed: 16445550].

11. Ramo DE, Anderson KG, Tate SR, Brown SA. Characteristics of relapse to substance use in comorbid adolescents. Addict Behav. 2005;30(9):1811-23. doi: 10.1016/j.addbeh.2005.07.021. [PubMed: 16139961].

12. McKay JR, Foltz C, Leahy P, Stephens R, Orwin RG, Crowley EM. Step down continuing care in the treatment of substance abuse: correlates of participation and outcome effects. Eval Program Plann. 2004;27(3):321-31. doi:10.1016/j.evalprogplan.2004.04.005. 
13. Walton MA, Blow FC, Bingham CR, Chermack ST. Individual and social/environmental predictors of alcohol and drug use 2 years following substance abuse treatment. Addict Behav. 2003;28(4):627-42. [PubMed:12726780].

14. Vielva I, Iraurgi I. Cognitive and behavioural factors as predictors of abstinence following treatment for alcohol dependence. Addiction. 2001;96(2):297-303. doi: 10.1080/09652140020021035. [PubMed: 11182875].

15. Maisto SA, Connors GJ, Zywiak WH. Alcohol treatment, changes in coping skills, self-efficacy, and levels of alcohol use and related problems 1 year following treatment initiation. Psychol Addict Behav. 2000;14(3):257-66. [PubMed: 10998951].

16. Solomon KE, Annis HM. Outcome and efficacy expectancy in the prediction of post-treatment drinking behaviour. $\mathrm{Br} J$ Addict. 1990;85(5):659-65. [PubMed: 2354283].

17. Davis MI, Jason LA. Sex differences in social support and self-efficacy within a recovery community. Am J Community Psychol. 2005;36(34):259-74. doi: 10.1007/s10464-005-8625-z. [PubMed:16389499].

18. Taylor SE, Welch WT, Kim HS, Sherman DK. Cultural differences in the impact of social support on psychological and biological stress responses. Psychol Sci. 2007;18(9):831-7. doi: 10.1111/j.14679280.2007.01987.x. [PubMed: 17760781].

19. Lee EH, Yae Chung B, Boog Park H, Hong Chun K. Relationships of mood disturbance and social support to symptom experience in Korean women with breast cancer. J Pain Symptom Manage. 2004;27(5):425-33. doi:10.1016/j.jpainsymman.2003.10.007. [PubMed: 15120771].

20. Atadokht A, Hajloo N, Karimi M, Narimani M. The role of family expressed emotion and perceived social support in predicting addiction relapse. Int J High Risk Behav Addict. 2015;4(1):ee21250. doi: 10.5812/ijhrba.21250. [PubMed: 25883918].

21. Nashee Q, Amjad N, Rafique R, Naz A. Perceive social support and relapse proneness in persons with substance use disorders. J Addict Res Ther. 2014;5(3):111-20.

22. Lemos Vde A, Antunes HK, Baptista MN, Tufik S, Mello MT, Formigoni
ML. Low family support perception: a 'social marker' of substance dependence?. Rev Bras Psiquiatr. 2012;34(1):52-9. [PubMed: 22392389].

23. Martin-Storey A, Serbin LA, Stack DM, Ledingham JE, Schwartzman AE. Self and peer perceptions of childhood aggression, social withdrawal and likeability predict adult substance abuse and dependence in men and women: a 30-year prospective longitudinal study. Addict Behav. 2011;36(12):1267-74. doi:10.1016/j.addbeh.2011.07.043. [PubMed: 21889853].

24. Jason LA, Davis MI, Ferrari JR. The need for substance abuse after-care: longitudinal analysis of Oxford House. Addict Behav. 2007;32(4):80318. doi: 10.1016/j.addbeh.2006.06.014. [PubMed: 16843612].

25. Atkins RG JR, Hawdon JE. Religiosity and participation in mutual-aid support groups for addiction. J Subst Abuse Treat. 2007;33(3):321-31. doi:10.1016/j.jsat.2007.07.001. [PubMed:17889302].

26. Ellis B, Bernichon T, Yu P, Roberts T, Herrell JM. Effect of social support on substance abuse relapse in a residential treatment setting for women. Eval Program Plann. 2004;27(2):213-21.

27. MacDonald EM, Luxmoore M, Pica S, Tanti C, Blackman JM, Catford $\mathrm{N}$, et al. Social networks of people with dual diagnosis: the quantity and quality of relationships at different stages of substance use treatment. Community Ment Health J. 2004;40(5):451-64. [PubMed: 15529478].

28. Sherer M, Maddux JE, Mercandante B, Prentice-Dunn S, Jacobs B, Rogers RW. The self-efficacy scale: Construction and validation. Psychol Rep. 1982;51(2):663-71.

29. Haghayegh SA, Ghasemi N, Neshardoost HT, Kajbaf MB, Khanbani M. The determining the psychometric properties of the Diabetes Management Self - Efficacy Scale (DMSES) in type II diabetes patients. Psy Prop. Diabetes Managem. 2010;12(2):111-5.

30. Zimet GD, Dahlem NW, Zimet SG, Farley GK. The Multidimensional Scale of Perceived Social Support. J Pers Assess. 1988;52(1):30-41. doi: 10.1207/s15327752jpa5201_2.

31. Zaki MA. Adaptation to University and Its Relationship with Social Support A case study: the Students of Isfahan University. ISSN. 2008;4:107-30. 